PT, một số chăm sóc và kỹ thuật chuyên sâu trong gây mê, cập nhật một số thuốc mê mới, sử dụng máy mê, máy thở, máy sốc tim và công tác kiểm soát nhiếm khuẩn phòng mổ.

\section{TÀI LIẸU THAM KHẢO}

1.Vũ Đình Chính, Trân Thi Minh Tâm, Đinh Thi Diệu Hằng (2005), "Đánh giá thực trạng nguồn nhẩn lực kỹ thuât viến y tế tai các bềnh viến thuốc 28 tỉnh phía bắc", tạp chí y học thực hành ${ }_{\llcorner}$526, 7-10.

2.Nguyến Thị Thu Hà (2016), Nguyến Thị Thu Hà (2016), "Thực trạng kiên thức về kiểm soát nhiễm khuân bệnh viển của điều dưỡng viên hồi sức tích cức, bềnh viền Hữu nghi Viêtt Đức năm 2015", tạp chí y học dự phòng, Tập XXVI, số 15 (188)
3.Farid Najafi (2017), Knowledge, Attitude and Practice of Nurses Regarding Nosocomial Infections Control in Teaching Hospitals of Kermanshah University of Medical Sciences, Iran . Arch Hyg Sci, 6(4), 314- 319.

4.Nguyễn Việt Thăng (2014), Thực trạng nguồn nhân lực điều dướng, hộ sinh, kỹ thuật viên tại các cơ sở y tế công lập Hà tî̉nh năm 2014.

5.Trường đại học Kỹ thuật $\mathbf{Y}$ tế Hải Dương, Bản so sánh các trỉnh độ trung cấp - cao đẳng - đại học - của Chương trình dạy học điều dưỡng Gây mê hồi sức trường đại học Kỹ thuật $Y$ tế Hải Dương năm 2018.

6. Trường đại học Kỹ thuật $Y$ tế Hải Dương, Chương trình giáo duc đại học điều dưỡng Gây mế hồi sức trường đại học Kỹ thuật $Y$ tế Hải Dương năm 2018.

\title{
KHẢO SÁT CÁC CHỈ SỐ ALBUMIN - BILIRUBIN Ở BÊNNH NHÂN XƠ GAN CÓ UNG THƯ BIỂU MÔ TẾ BÀO GAN
}

\section{TÓM TẮT}

Mục tiêu: Bệnh nhân ung thư biểu mô tế bào gan (HCC) thường xuất hiên trên nền gan xớ. Nghiên cứu chúng tôi với mục tiểu áp dụng phân loại albuminbilirubin (ALBI) trong đánh giá chức năng gan. Đối tượng và phương pháp: Trong nghiên cứu chúng tôi tuyển chon được 224 bênh nhân $\mathrm{HCC}$ từ năm 2018-2019 tất cả bệnh nhân được tính toán chỉ số ALBI và phân loại Child-Pugh, phân loại Barcelona (BCLC). Kết quả: Tổng số 224 bệnh nhẩn HCC (186 nam và 38 nữ, tuổi trung bình, 28 - 90 tuổi, trung bình là 59 tuối) được đánh giá chỉ số ALBI. Bệnh nhân HCC được phân chia giai đoạn theo BCLC giai đoạn A (20.2\%), BCLC giai đoạn B $(45.7 \%)$, BCLC giai đoạn C (23.8\%) và giai đoạn D (10.3\%). Điểm ChildPugh và phân loại theo ALBI và $B C L C$ có sự tương đồng về mức độ giai đoạn. Kết luận: Nghiên cứu cho thấy rằng chỉ sổ albumin-bilirubin (ALBI) là một yếu tố có khả năng dự báo chức năng gan theo phân loại Child-pugh và BCLC ở bệnh nhân HCC.

Tư khóa: Ung thư biểu mô tế bào gan (HCC); Albumin-bilirubin (ALBI); Child-Pugh (CP)

\section{SUMMARY}

ASSESSMENT OF THE ALBUMIN-BILIRUBIN (ALBI) GRADE FOR HEPATOCELLULAR CARCINOMA PATIENTS WITH CIRRHOSIS

Objective: Hepatocellular carcinoma (HCC) in patients with cirrhosis frequently reported. We

\footnotetext{
1Trung tâm tiêu hóa gan mật bệnh viện Bạch mai 2Bệnh viện đa khoa tỉnh Hải Dương Chịu trách nhiệm chính: Nguyễn Công Long Email: nguyenconglongbvbm@gmail.com Ngày nhận bài: 11.10.2021 Ngày phản biện khoa học: 13.12.2021 Ngày duyệt bài: 21.12.2021
}

\section{Nguyễn Công Long1, Đàm Thị Phương²}

evaluated the usefulness of albumin-bilirubin(ALBI) grade as a tool for assessment of hepatic reserve function. Subjects and methods: We enrolled 224 HCC patients from 2018-2019. Child-Pugh classification and ALBI grading were calculated. Results: A total of $224 \mathrm{HCC}$ patients (186 males and 38 females, age range, $28-90$ years, average age, 59 years) were valuated ALBI. According to BCLC classification, BCLC stage A $(20.2 \%)$, BCLC stage $B(45.7 \%)$, and BCLC stage $C(23.8 \%)$ and stages $D(10.3 \%)$. Child-Pugh clasifications and ALBIbased BCLC systems were highly concordant. Conclusions: the albumin-bilirubin (ALBI) grade, as a prognosticator has demontrated that was correlated with Child-pugh clasification and BCLC stages in HCC patients.

Keywords: Hepatocellular carcinoma (HCC); Albumin-bilirubin (ALBI); Child-Pugh (CP)

\section{I. ĐẶT VẤN ĐỀ}

Hầu hết bệnh nhân ung thư biểu mô tế bào gan có liên quan đến bệnh gan mạn tính, thường trên nền xơ gan phát triển thành HCC. Tỉ lệ sống còn của bệnh nhân HCC phụ thuộc giai đoạn khối u và chức năng gan[1]. Ngoài ra năm 2015 phân điểm ALBI được đề xuất để đánh giá chức năng gan của bệnh nhân. Chỉ số này gồm hai yếu tố khách quan là Albumin và bilirubin toàn phần[2]. Một số điều tra đã xác nhận rằng điểm ALBI tốt hởn điểm Child-Pugh khi dự báo chức năng gan của bệnh nhân cũng như tiên lượng của bệnh nhân sau khi cắt bỏ gan và điều trị bằng phóng xạ hay đốt sóng cao tần[3]. Ở Việt Nam nền kinh tế còn nhiều khó khăn, việc đánh giá chức năng gan cũng như tiên lượng bệnh nhân ung thư biểu mô tế bào gan dựa vào chỉ số ALBI là phương pháp mới khách quan, dễ triển 
khai và áp dung ngay cả ở các tuyến cơ sở. Vì vậy chúng tôi tiến hành nghiên cứu này nhằm tìm hiểu giá trị phối hợp Albumin- Bilirubin và tiểu cầu trong dự bào chức năng gan và giãn tĩnh mach thực quản ở bênh nhân ung thư biểu mô tế bào gan.

\section{II. ĐỐI TƯỢNG VÀ PHƯƠNG PHÁP NGHIÊN CỨU}

Đối tượng: Bệnh nhân được chẩn đoán ung thư biểu mô tế bào gan, điều trị nội trú và ngoại trú tại khoa Tiêu hóa - Bệnh viện Bạch Mai từ tháng 9/2018 đến tháng 5/2019.

- Bênh nhân được chẩn đoán xác định là HCC bằng một trong các tiêu chuẩn sau (theo Bộ Y tế 2012)

+ Có bằng chứng giải phẫu bệnh lý là HCC

+ Hình ảnh điển hình trên $\mathrm{CT}$ hoăc $\mathrm{CHT}$ ổ bụng có cản quang + nồng độ AFP $>400 \mathrm{ng} / \mathrm{ml}$

+ Hình ảnh điển hình trên $\mathrm{CT}$ hoặc $\mathrm{CHT}$ ổ bụng có cản quang + nồng độ AFP tăng trên bình thường (nhưng $<400 \mathrm{ng} / \mathrm{ml}$ ) + có nhiễm virus viêm gan $B$ hoặc $C$.

Chẩn đoán hình ảnh điển hình: có dấu hiệu thải thuốc, cụ thể là tổn thương bắt thuốc nhanh ở thì động mạch và trải thuốc nhanh ở thì tĩnh mach cửa hoăc thì muôn.

Phương pháp nghiên cứu:

*Tất cả bệnh nhân vào nghiên cứu đều được hỏi bệnh và khám bệnh một cách tỉ mỉ theo mẩu bệnh án thống nhất. Ghi lại những triệu chứng lâm sàng: mệt mỏi, ăn kém, gây sút, sốt, đau hạ sườn phải, đầy bụng, gan to, lách to, phù, cổ trướng, thiếu máu, vàng da, đau bụng cấp tính.

*Chỉ định cận lâm sàng: Các xét nghiệm và phương pháp chẩn đoán hình ảnh được tiến hành tại Bệnh viện Bạch Mai.

- Xét nghiệm AFP huyết thanh.

-Dấu ấn của viêm gan virus: $\mathrm{HBsAg}$, anti HCV, HBV DNA.

- Sinh hóa máu: ure, creatinin, glucose, protein máu toàn phần, albumin, transaminae (AST, $A L T$ ) và $G G T$, bilirubin toàn phần

-Chỉ số albumin-bilirubin(ALBI)

- Tế bào máu ngoại vi: hồng cầu, hemoglobin, bạch cầu, công thức bạch cầu, tiểu câuu

- Xét nghiêm đông máu cơ bản: Prothrombin, INR

- Siêu âm: hình ảnh siêu âm của khối HCC có thể là khối giảm âm, tăng âm hoặc hỗn hợp âm, có thể có dấu hiệu mắt trâu, thể lan tỏa...Đánh giá vị trí, số lượng, kích thước, tính chất di căn khối u.

- Siêu âm Doppler: có tăng sinh mạch trong khối, đánh giá tình trạng tĩnh mạch cửa...

- Chụp CLVT: chụp CLVT xoắn ốc 3 pha khi chưa tiêm thuốc cản quang: khối u giảm tỷ trọng so với nhu mô gan. Pha động mạch, khối ngấm thuốc nhanh. Pha tĩnh mạch cửa, khối u hầu như không ngấm thêm thuốc cản quang. Pha muộn, khối thoát thuốc nhanh và đánh giá vị trí, số lượng, kích thước, tính chất di căn khối u.

Xử lý số liệu: Sau khi thu thập đầy đủ các số liệu, quá trình xử lý được làm trên máy tính với phần mềm xử lý số liệu SPSS 16.0, tính hệ số tương quan $r$, giá trị $P<0,05$ được xác định là mức khác biệt có ý nghĩa thống kê.

\section{KẾT QUẢ NGHIÊN CỨU}

Bảng 1. Tiền sử bản thân và gia đình của $B N$ $\operatorname{HCC}(n=224)$

\begin{tabular}{|c|c|c|}
\hline Tiền sử & $\begin{array}{c}\text { Số bệnh } \\
\text { nhấn }\end{array}$ & $\begin{array}{c}\text { Tỷ lệ } \\
(\%)\end{array}$ \\
\hline \multicolumn{2}{|c|}{ Tiền sử bản thân } \\
\hline HBV & 112 & 50,0 \\
\hline HBV + Rượu & 57 & 25,5 \\
\hline Rượu & 38 & 17,0 \\
\hline HBV + HCV & 7 & 3,1 \\
\hline HCV & 5 & 2,2 \\
\hline Đái tháo đường & 3 & 1,3 \\
\hline Không rõ nguyên nhân & 2 & 0,9 \\
\hline $\begin{array}{c}\text { Tiền sử gia đình mắc } \\
\text { bệnh HCC }\end{array}$ & 14 & 6,3 \\
\hline
\end{tabular}

Tỷ lê bênh nhân có mắc virus HBV là lớn nhất chiếm $50,0 \%$. Tỷ lệ bệnh nhân nghiện rượu là $17,0 \%$ và bệnh nhân vừa có $\mathrm{HBV}$ vừa nghiện rượu là $25,4 \%$.

Bảng 2. Đặc điểm khối u của 224 bệnh nhân HCC \begin{tabular}{|l|l|l|}
\hline Một số đặc điểm & Số bệnh nhân & Tỷ lệ \% \\
\hline
\end{tabular}

\begin{tabular}{|c|c|c|}
\hline \multicolumn{3}{|c|}{ Vị trí u } \\
\hline Gan phải & 142 & 63,4 \\
\hline Gan trái & 52 & 23,2 \\
\hline Lan tỏa & 30 & 13,4 \\
\hline \multicolumn{3}{|c|}{ Số lượn u } \\
\hline 1 u & 119 & 53,2 \\
\hline 2 u & 46 & 20,5 \\
\hline 3 u & 13 & 5,8 \\
\hline Từ 3 u trở lên & 46 & 20,5 \\
\hline \multicolumn{3}{|c|}{ Kích thước u } \\
\hline$<2$ cm & 44 & 19,6 \\
\hline $2-3$ cm & 90 & 40,2 \\
\hline$>3$ cm & 90 & 40,2 \\
\hline Tăng sinh mạch (n=179) \\
\hline Có & 170 & 95,0 \\
\hline Không & 9 & 5,0 \\
\hline
\end{tabular}

Tỷ lệ khối u nằm ở gan phải là cao nhất chiếm $63,4 \%$, ở gan trái là $23,2 \%$ và thấp nhất là lan tỏa với $13,4 \%$.

Bảng 3. Phân loại HCC theo thang điêm Barcelona (BCLC) 


\begin{tabular}{|c|c|c|}
\hline Phân loại BCLC & Số bệnh nhân & Tỷ lệ \% \\
\hline A & 45 & 20,2 \\
\hline B & 102 & 45,7 \\
\hline C & 53 & 23,8 \\
\hline D & 23 & 10,3 \\
\hline
\end{tabular}

\begin{tabular}{|c|c|c|c|}
\hline \multicolumn{2}{|c|}{ Tống } & 224 & 100 \\
\hline \multicolumn{4}{|c|}{$\begin{array}{l}\text { Phân loại bệnh nhân HCC theo thang điếm } \\
\text { Barcelona cho thấy tỷ lệ bệnh nhân ở mức độ B } \\
\text { là lớn nhất chiếm } 45,7 \% \text {. Tỷ lệ thấp nhất là } \\
10,3 \% \text { ở mức độ } D \text {. }\end{array}$} \\
\hline \multicolumn{4}{|c|}{$\operatorname{lgh}(N=224)$} \\
\hline & B & C & $\mathbf{p}$ \\
\hline & $3(6,7)$ & $0(0)$ & \multirow{3}{*}{0,000} \\
\hline 4) & $29(64,4)$ & $1(4)$ & \\
\hline & $13(28,9)$ & $24(96)$ & \\
\hline 00) & $45(100)$ & $25(100)$ & \\
\hline
\end{tabular}

Bảng 4. Đối chiêu chi số ALBI với chi số Child Pugh $(N=224)$

\begin{tabular}{|c|c|c|c|c|}
\hline Phân loại Child-Pugh & A & B & C & p \\
Phân điểm ALBI & $60(39)$ & $3(6,7)$ & $0(0)$ & \multirow{2}{*}{0,000} \\
\hline Phân điếm ALBI = 1 & $93(60,4)$ & $29(64,4)$ & $1(4)$ & \\
\hline Phân điếm ALBI = & $1(0,7)$ & $13(28,9)$ & $24(96)$ & $\mathbf{2 5 ( 1 0 0 )}$ \\
\hline Phân điếm ALBI = 3 & $\mathbf{1 5 4 ( 1 0 0 )}$ & $\mathbf{4 5 ( 1 0 0 )}$ & $\mathbf{2 5}$ \\
\hline
\end{tabular}

Ơ giai đoạn Child Pugh $A$ thì hâuu hết bệnh nhân thuộc ALBI 1 và 2 (39\% và 60,4\%), Child Pugh $B$ thì $A L B I-2$ và 3 là chủ yếu (64,4\% và $28,9 \%)$. Child Pugh C thì $96 \%$ bệnh nhân thuộc ALBI-3.

Bảng 5. Mối liên quan giữa điểm ALBI và giãn TMTQ trên bệnh nhần

\begin{tabular}{|c|c|c|c|c|}
\hline Phân điểm ALBI & Có HRV & $\begin{array}{l}\text { Không } \\
\text { HRV }\end{array}$ & $\begin{array}{c}\text { OR } \\
(95 \% \mathrm{CI})\end{array}$ & $\mathbf{p}$ \\
\hline Phân điếm ALBI $\geq 2$ & 80 & 81 & \multirow{3}{*}{$\begin{array}{c}7,9 \\
(3,2-19,5)\end{array}$} & \multirow{3}{*}{0,000} \\
\hline Phân điếm ALBI = 1 & 7 & 56 & & \\
\hline Tống & 87 & 137 & & \\
\hline
\end{tabular}

Bệnh nhân có phân điểm ALBI $\geq 2$ có nguy cơ có HRV (Giãn tĩnh mạch thực quản nguy cơ cao) cao gấp 7,9 lần phân điểm ALBI = $1(95 \% \mathrm{CI}: 3,2-19,5)$. Sự khác biệt có ý nghĩa thống kê với $p<0,01$.

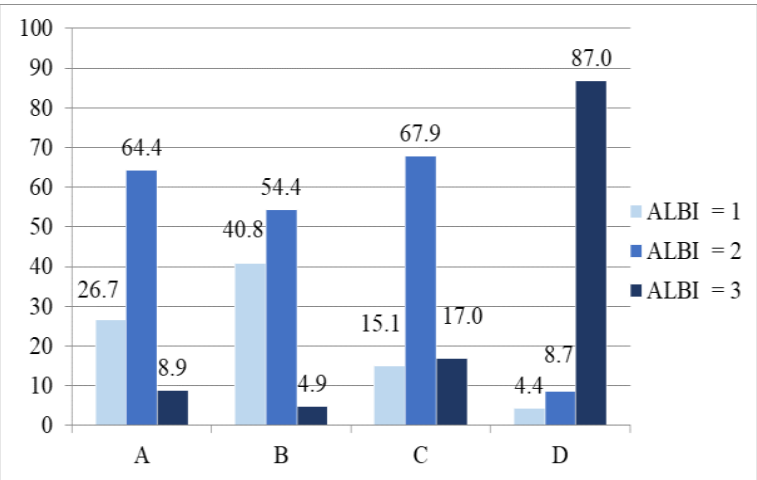

Biểu đồ 1. Tỷ lệ từng nhóm theo ALBI trong các giai đoan ung thu' gan Barcelona $(N=224)$

Giai đoạn $B C L C A$; $B$ và $C$ thì chủ yếu bệnh nhân thuộc nhóm ALBI-2, giai đoạn BCLC D có 87\% bệnh nhân thuộc nhóm ALBI - 3.

\section{BÀN LUẬN}

Trong nghiên cứu 224 bệnh nhân ung thư gan chúng tôi nhận thấy có nhiều yếu tố nguy cơ gây bệnh xơ gan và ung thư gan, trong đó tỷ lệ HBV là yếu tố cao nhất, có 176 bệnh nhân chiếm 78,5\% số bệnh nhân. Về phân loại xơ gan theo phân loại Child-Pugh: Trong nghiên cứu của chúng tôi với 224 bệnh nhân xơ gan có UTBMTBG có $154(68,8 \%)$ bệnh nhân xơ gan Child-Pugh A, $45(20,1 \%)$ bệnh nhân xơ gan Child-Pugh B, $25(11,1 \%)$ bệnh nhân xơ gan $C$, kết quả nghiên cứu của chúng tôi phù hợp với nghiên cứu của Chen PH (2017) trên 1283 bệnh nhân UTBMTBG với 70,4\% Child-Pugh A, 23,3\% Child-Pugh B, 6,3\% Child-Pugh C. Giai đoạn UTBMTBG theo Barcelona: Trong nghiên cứu của chúng tôi, giai đoạn BCLC 0 không có bệnh nhân nào, giai đoạn $A: 20,2 \%$ (45BN); $B: 45,7 \%$ $(102 \mathrm{BN}) ; \mathrm{C}: 23,8 \%$ (53BN); D: $10,3 \%$ (23BN). Về phân loại theo điểm ALBI với, Trong nghiên cứu của chúng tôi có 224 bệnh nhân được phân thành các phân lớp ALBI khác biệt $(p<0,01)$ : Trong đó có phân điểm ALBI $=1$ chiếm $28,1 \%$, phân điểm ALBI $=2$ chiếm $54,9 \%$, phân điểm ALBI = 3 chiếm 17,0\% tương tự một số nghiên cứu khác $[4,5]$. Theo nghiên cứu của Jonhson (2015) nghiên cứu trên đoàn hệ ở Nhật Bản có 2596 bệnh nhân được phân thành các lớp ALBI riêng biệt với thời gian sống sót khác nhau với phân điểm $A L B I=1$ có $650 B N(25,1 \%)$ thời gian sống thêm trung bình là 85,6 tháng, phân điểm ALBI=2 có $1699 B N(65.4 \%)$ thời gian sông thêm trung bình là 46,5 tháng, phân điểm ALBI=3 có 247BN $(9,5 \%)$ thời gian sống thêm trung bình là 15,5 tháng[2]. Như vậy có thể thấy điểm ALBI trong đánh giá chức năng gan ở bệnh nhân xơ gan có UTBMTBG tăng tương ứng với mức độ nặng của chức năng gan theo phân loại ChildPugh. Do đó có thể sử dụng phân điểm ALBI để đánh giá chức năng gan ở bệnh nhân xơ gan có ung thư biểu mô tế bào gan.

\section{KẾT LUÂ̂N}

Trong thời gian từ tháng $8 / 2018$ đến tháng 6/2019 chúng tôi đã tiến hành nghiên cứu khảo 
sát các chỉ số Albumin-Bilirubin ở bênh nhân xơ gan có ung thư biểu mô tế bào gan với số lượng 224 BN và có kết luân như sau: Phân điểm ALBI tăng dần theo mức độ nặng của UTBMTBG theo phân loại Child-Pugh và phân loại Barcelona.

\section{TÀI LIẸU THAM KHẢO}

1. Bosch, F.X., et al. Primary liver cancer: worldwide incidence and trends. Gastroenterology, 2004. 127(5 Suppl 1): p. S5-s16.

2. Johnson, P.J., et al., Assessment of liver function in patients with hepatocellular carcinoma: a new evidence-based approach-the ALBI grade. J Clin
Oncol, 2015. 33(6): p. 550-8.

3. Toyoda, $\mathbf{H}_{\text {., }}$ et al., Long-term impact of liver function on curative therapy for hepatocellular carcinoma: application of the ALBI grade. $\mathrm{Br}$ J Cancer, 2016. 114(7): p. 744-50.

4. Gui, B., et al., Assessment of the AlbuminBilirubin (ALBI) Grade as a Prognostic Indicator for Hepatocellular Carcinoma Patients Treated With Radioembolization. Am J Clin Oncol, 2018. 41(9): p. 861-866.

5. Wang, Y.Y., et al., Albumin-bilirubin versus ChildPugh score as a predictor of outcome after liver resection for hepatocellular carcinoma. The British journal of surgery, 2016. 103.

\section{ĐĂC ĐIỂM LÂM SÀNG VÀ CHẤT LƯợNG CUộC SỐNG CỦA NGƯỜI BÊ̂NH ĐộNG KINH TẠI TRUNG TÂM THẦN KINH, BÊ̂NH VIỆN BACCH MAI NĂM 2020 - 2021}

\section{TÓM TẮT}

Nghiên cứu mô tả cắt ngang thực hiện trên 385 bênh nhân tại Trung tâm Thẩn kinh - Bệnh viện Bach Mai từ tháng 12/2020 đến tháng 08/2021. Mục tiểu: Mô tả đắc điểm lâm sàng và chất lượng cuộc sống của người bệnh động kinh tại Trung tâm Thần kinh - Bệnh viện Bạch Mai. Số liệu thu thập được từ bệnh án nghiên cứu về chất lượng cuộc sống. Số bệnh nhân tuổi $\geq 40$ chiếm đa số với $54,3 \%$, tuổi trung bình là $44,49 \pm 17,89$. Nam giới chiếm tỷ lệ cao hơn nữ giới (65,2\% so với $34,8 \%) ;$ Trình độ học vấn: Từ Trung học phổ thông chiếm đa số với 55,9\%. Hôn nhân: đa sổ người bệnh có gia đình với 64,2\%; Kinh tễ: Hỗ không nghèo: 95,3\%; Hộ nghèo/ Cận nghèo: 4,7\%; Ớ thành thị cao hớn nông thôn (53,2\% so với $46,8 \%)$. Nghề nghiêp: cán bô công nhân viên $(61 \%)$, nông dân $(28,1 \%)$; Hoàn cảnh sống cùng gia đình chiếm đa số với $96,9 \%$; Có bảo hiểm y tế chiếm đa số với $81,3 \%$; thời gian mắc bệnh <5 năm $(74 \%) ;>5$ năm (26\%). Hoàn cảnh xảy ra cớn chiếm tỷ lệ cao nhất khi đang làm việc (32,5\%). Đặc điểm người bệnh khi có cơn: Dấu hiệu báo trước cởn chiếm đa số là không có triệu chứng $(51,9 \%)$, nhức đâu $(20,5 \%)$, tê bì chân tay $(11,4 \%)$. Tần số cơn > 1 cơn/ngày $(57,1 \%),>1$ cơn /tháng nhưng không > 1 cơn/tuần $(14,3 \%)$, > 1 cơn/tuân $(13,8 \%), \geq 1$ cơn/ năm $(11,7 \%)$. không có cơn/năm qua chỉ 3,1\%. Tổng điểm QOLIE trung bình: $57,71 \pm 10,51$; Mức độ CLCS kém chiếm tỷ lệ cao nhất là $50,6 \%$.

Tư khóa: động kinh, chất lượng cuộc sống, người bệnh, bệnh viện.

${ }^{1}$ Bệnh viện Bạch Mai

2 Trường Đai hoc Thăng Long

Chịu trách nhiệm chính: Bùi Thị Liên

Email: lientbvn@gmail.com

Ngày nhân bài: 18.10.2021

Ngày phản biên khoa hoc: 14.12.2021

Ngày duyệt bài: 22.12.2021

\section{CLINICAL CHARACTERISTICS AND QUALITY OF LIFE OF EPILEPSY PATIENTS AT CENTER OF NEUROLOGY - BACH MAI HOSPITAL, 2020 - 2021}

SUMMARY

A cross-sectional descriptive study on 385 patients at Centre of Neurology - Bach Mai Hospital from December 2020 to August 2021. Objective: describe the clinical characteristics and quality of life of epilepsy patients at Centre of Neurology - Bach Mai hospital. The prevalence of men was higher than women $(65.2 \%$ compared to $34.8 \%)$, average age: $44.49 \pm$ 17,89. Education level: above high school education accounts for the highest: $55.9 \%$. Marriage status: married: $64.2 \%$. Socioeconomic status: non-poor households: $95.3 \%$; poor/near poor households: $4.7 \%$. Resedency area: urban area was higher than rural area (53.2\% compared to $46.8 \%)$. Occupation: civil servant $(61 \%)$, farmer $(28.1 \%)$. The prevalence of patients have health insurance was $81.3 \%$; disease duration less than 5 years accounted for $74 \%$; $>5$ years. Onset time: working (32.5\%), sleeping $(26.5 \%)$, heavy labor/fatigue $(17.7 \%)$, walking (8.8\%). Onset symptom: without symptoms $(51.9 \%)$, headache $(20.5 \%)$, numbness in limbs $(11.4 \%)$. Frequency of attacks $>1$ attack per day $(57.1 \%)$, only $3,1 \%$ of patients have free seizure in a year. Total average QOLIE score: $57.71 \pm 10.51$, in which low level - quality of life accounted for highest prevalence $(50,6 \%)$.

Keywords. epilepsy, quality of life, patient, hospital.

\section{I. ĐĂT VẤN ĐỀ}

Động kinh (ĐK) là một tình trạng bệnh lý của não dọo nhiều nguyên nhân khác nhau gây ra với bệnh cảnh rất phức tạp và đa dạng. Bệnh có thể gặp ở mọi lứa tuổi, mọi giới. Theo thống kê của Tổ chức $Y$ tế Thế giới (WHO), tỷ lệ người mắc 